\title{
DISTRIBUTION AND PATTERN OF VALVULAR HEART DISEASES BY ECHOCARDIOGRAPHY: A TERTIARY CARE CENTER STUDY
}

Vaishali Bhalavi1 ${ }^{1}$ B. S. Yadav²

${ }_{1}^{1}$ Senior Resident, Department of General Medicine, Gandhi Medical College, Bhopal.

2 Professor, Department of Cardiology, Gandhi Medical College, Bhopal.

\section{ABSTRACT}

\section{BACKGROUND}

The current study was undertaken at tertiary care center, Bhopal, MP, Central India, with the objective of establishing distribution and patterns of valvular heart diseases by echocardiography.

\section{MATERIALS AND METHODS}

10,000 consecutive cases undergoing echocardiography in the Cardiology Department Hamidia Hospital, Bhopal, between January 2009 and July 2011 were analysed. Echo was performed by consultant cardiologists using Acuson Aspen machine following ASE guidelines. 1758 cases of valvular heart diseases were found and based on world health federation echocardiographic criteria for the diagnosis of rheumatic heart diseases we found the RHD in the present study.

\section{RESULTS AND CONCLUSIONS}

In the present study of 10,000 cases, 1758 cases of Valvular heart diseases were found with mitral valve most commonly affected followed by aortic and tricuspid valve and least affected was pulmonary valve. Among isolated lesions, MS with MR was the commonest lesion and is most prevalent in females between 31-45 yrs. age.

\section{KEYWORDS}

Valvular Heart Diseases, Occurrence of VHD, Echocardiography, Central India.

HOW TO CITE THIS ARTICLE: Bhalavi V, Yadav BS. Distribution and pattern of valvular heart diseases by echocardiography: a tertiary care center study. J. Evolution Med. Dent. Sci. 2016;5(27):1394-1399, DOI: 10.14260/jemds/2016/329

\section{INTRODUCTION}

Valvular Heart Diseases (VHD) is the leading cause of morbidity and mortality in India. Rheumatic heart diseases continue to be the dominant form in developing nations. ${ }^{1}$ Data obtained by echocardiography, some autopsy..$^{2-4}$ and surgical pathology..$^{5-8}$ are rich source of studying prevalence of VHD. Advances in both surgical and percutaneous techniques and better understanding of timing of intervention accounts for the current increased in rate of survival. Echo remains the gold standard for diagnosing and periodic assessment of patterns of VHD. Stenotic lesions patients can be monitored and benefited from percutaneous technique and regurgitant lesions require surgery. Echo is the main tool in diagnosing valvular anatomy, morphology and haemodynamics effects of VHD.

Prevalence of rheumatic heart diseases varies among different nations. In the developed countries there is decrease in incidence of rheumatic fever and the prevalence of rheumatic heart diseases, but in developing countries RHD has continued to be major health concern. In India, the prevalence of rheumatic fever and rheumatic heart diseases among school children is $2-11$ per 1000 with a mean of 6 per 1000 (Padmawati et al.). ${ }^{9}$ ICMR. ${ }^{10}$ has conducted three school-based surveys in children 5 to 14 yrs. in age over a 40 -year period between 1970 and 2010 .

Financial or Other, Competing Interest: None.

Submission 10-02-2016, Peer Review 08-03-2016,

Acceptance 16-03-2016, Published 04-04-2016.

Corresponding Author:

Vaishali Bhalavi,

B-3/76, Sahara States, Bhojpur Road,

Bhopal-462047,

Madhya Pradesh.

E-mail:dr.vaishalibhalavi@gmail.com

DOI: $10.14260 /$ jemds $/ 2016 / 329$
The first survey from 1972 to 1975 was in schools at Agra, Alleppey, Bombay (Mumbai), Delhi and Hyderabad. The second from 1984 to 1987 included schools at Delhi, Varanasi and Vellore. The third study included children from 10 centers in the country located at Shimla, Jammu, Chandigarh, Jodhpur, Indore, Kochi, Wayanad, Mumbai, Vellore and Dibrugarh. It has a wider coverage, but not of the whole country. In the first study (1972-1975), 1,33,000 children were evaluated and the prevalence of RHD varied from 0.8 to $11 / 1000$, overall $5.3 / 1000$. The second study (1984-1987) included 53,786 children and the prevalence ranged from 1.0 to 5.6/1000 overall 2.9/1000. The third and the largest study included $1,76,904$ school children with a prevalence varying from 0.13 to $1.5 / 1000$ (Overall $0.9 / 1000$ ) in the 5 to 14 yrs. age range.

The data suggests a progressive decline in RHD from 5.3 to 2.9 to below $1.0 / 1000$ between 1970 and 2010. In the last study, echocardiographic evaluation was performed in all children clinically diagnosed to have a heart murmur and children with congenital heart disease could be excluded. In a study on 1,18,212 school children 4-18 yrs. in age a heart murmur was found in 389 normal children. Echo evaluation identified 61 children with RHD giving a prevalence of 0.5/1000 children in Uttar Pradesh. Studies from Punjab, Gujarat, Rajasthan, Uttar Pradesh and Tamil Nadu have found the prevalence to range from 0.67 to $4.54 / 1000$ children.

Prevalence of RHD in school children in different states in India as shown in Table 1.11,12,13,14,15,16,17,18 


\begin{tabular}{|c|c|c|c|}
\hline Place & Year & Age (Years) & Prevalence \\
\hline Punjab. ${ }^{11}$ & $\begin{array}{c}1988- \\
1991\end{array}$ & $5-15$ & 2.1 \\
\hline Gujrat. $^{12}$ & 1986 & $8-18$ & 2.03 \\
\hline Punjab. $^{13}$ & 1987 & $6-16$ & 1.3 \\
\hline Shimla. ${ }^{14}$ & $1992-93$ & $\begin{array}{c}5-15(\mathrm{Rural}) \\
5-15(\mathrm{Urban})\end{array}$ & $\begin{array}{c}4.8 \\
1.98\end{array}$ \\
\hline Uttarpradesh. $^{15}$ & 2000 & $7-15$ & 4.54 \\
\hline Tamilnadu. $^{16}$ & $2001-02$ & $5-18$ & 0.68 \\
\hline Rajasthan. $^{17}$ & 2006 & $5-14$ & 0.67 \\
\hline $\begin{array}{c}\text { Andhra } \\
\text { Pradesh. } 18\end{array}$ & 2011 & $5-16$ & 8.3 \\
\hline \multicolumn{3}{|c|}{ Table 1: Prevalence of RHD in School Survey } \\
\hline
\end{tabular}

The adult average ranges between 123 and 200 per 100,000 population (Mathur KS, et al.) ${ }^{19}$, when compared to industrialized nations the incidence of rheumatic fever is 0.5 per 100,000 population and the prevalence less than 0.05 per 1000 (Michaud C et al.) ${ }^{20}$, Prevalence of RHD in population survey (Table 2).

\begin{tabular}{|c|c|c|c|}
\hline Authors & $\begin{array}{c}\text { Age Group } \\
\text { (yrs.) }\end{array}$ & $\mathbf{N}$ & Prevalence \\
\hline Roy. ${ }^{21}$ & $5-30$ & 4847 & 2.2 \\
\hline Mathur. ${ }^{22}$ & $5-30$ & 7953 & 1.8 \\
\hline Berry. ${ }^{23}$ & $5-30$ & 19768 & 1.87 \\
\hline & All ages & 33361 & 1.55 \\
\hline Agarwal A.K.24 & All ages & 3760 & 6.4 \\
\hline \multicolumn{3}{|c|}{ Table 2: Prevalence of RHD in Population Survey } \\
\hline
\end{tabular}

\section{MATERIAL AND METHODS}

The present study was undertaken at Hamidia Hospital, Bhopal, MP, Central India. In the present study, 10,000 consecutive case undergoing echo between the period Jan 2009 and July 2011 were analysed. Echocardiography was performed by consultant cardiologist using Acuson Aspen machine following ASE guidelines. ${ }^{25}$ Among 10,000 cases undergoing echo 1758 cases of valvular heart diseases were found. Ours is a retrospective study with the objective of establishing distribution and patterns of valvular heart diseases in Hamidia Hospital, Bhopal (Madhya Pradesh), Central India.

\section{Inclusion Criteria}

Firstly, lesions were divided in two parts in our study: Isolated lesions and combinations of valvular lesions.
Secondly with the help of world health federation echocardiographic criteria. ${ }^{26}$ for rheumatic heart diseases (WHF echo criteria) we found the approximate percentage of RHD in Hamidia Hospital, Bhopal (M.P.), Central India.

\section{Exclusion Criteria}

Congenital lesions, degenerative diseases and other acquired causes were the exclusion criteria for rheumatic heart diseases in the present study and also the isolated regurgitant lesions either trivial, functional or unspecified causes were the exclusion criteria for RHD in the present study according to WHF echo criteria for RHD.

\section{RESULTS}

Out of 10,000 consecutive cases undergoing echocardiography in our study, 1758 cases of valvular heart diseases were found. Table 3 and 4 shows the distribution of valvular heart diseases in our study.

\begin{tabular}{|c|c|c|c|c|}
\hline VHD & $\begin{array}{c}\text { Total } \\
(\mathbf{N = 1 7 5 8 )}\end{array}$ & Percentage & $\begin{array}{c}\text { Male } \\
\mathbf{( \% )}\end{array}$ & $\begin{array}{c}\text { Female } \\
(\%)\end{array}$ \\
\hline ISOLATED MS & 333 & 18.9 & $103(30.9)$ & $230(69.1)$ \\
\hline ISOLATED MR & 289 & 16.4 & $127(43.9)$ & $162(56.1)$ \\
\hline ISOLATED AR & 175 & 9.9 & $106(60.6)$ & $69(39.4)$ \\
\hline BAV & 16 & 0.9 & $10(62.5)$ & $6(37.5)$ \\
\hline ISOATED AS & 15 & 0.85 & $11(73.3)$ & $4(26.6)$ \\
\hline ISOLATED TR & 16 & 0.9 & $7(43.8)$ & $9(56.3)$ \\
\hline ISOLATED PR & 2 & 0.1 & $1(50)$ & $1(50)$ \\
\hline $\begin{array}{l}\text { MULTIVALVULAR } \\
\text { HEART DISEASES }\end{array}$ & 912 & 51.8 & $406(44.5)$ & $506(55.5)$ \\
\hline \multicolumn{4}{|r|}{ Table 3: Distribution of Valvular Heart Diseases in our Study } \\
\hline
\end{tabular}

\begin{tabular}{|c|c|c|c|c|}
\hline $\begin{array}{c}\text { Multivalvular } \\
\text { Heart } \\
\text { Diseases }\end{array}$ & $\begin{array}{c}\text { Total } \\
\text { (N=912) }\end{array}$ & Percentage & $\begin{array}{c}\text { Male } \\
\mathbf{( \% )}\end{array}$ & $\begin{array}{c}\text { Female } \\
\mathbf{( \% )}\end{array}$ \\
\hline MS with MR & 373 & 40.9 & $136(36.5)$ & $237(63.5)$ \\
\hline MS with AR & 211 & 23.1 & $81(38.4)$ & $130(61.6)$ \\
\hline MS with AS & 46 & 5.0 & $27(58.6)$ & $19(41.3)$ \\
\hline MR with AR & 164 & 17.9 & $83(50.6)$ & $81(49.3)$ \\
\hline MR with AS & 28 & 3.1 & $23(82.1)$ & $5(17.8)$ \\
\hline AS with AR & 73 & 8 & $48(65.8)$ & $25(34.2)$ \\
\hline MS with TS & 12 & 1.3 & $5(41.6)$ & $7(58.3)$ \\
\hline MS with PS & 5 & 0.5 & $3(60)$ & $2(40)$ \\
\hline \multicolumn{6}{|r|}{ Table 4: Distribution of Multivalvular Heart Diseases in our Study } \\
\hline
\end{tabular}

\begin{tabular}{|c|c|c|c|c|c|c|c|c|c|c|c|}
\hline $\begin{array}{c}\text { Age } \\
\text { (yrs.) }\end{array}$ & MS & MR & AS & AR & BAV & TR & PR & MVD & Total & $\begin{array}{c}\text { Male } \\
(\%)\end{array}$ & $\begin{array}{c}\text { Female } \\
(\%)\end{array}$ \\
\hline $0-15$ & 15 & 81 & - & 15 & 6 & 4 & - & 91 & 212 & $94(44.3)$ & $118(55.6)$ \\
\hline $16-30$ & 132 & 58 & - & 61 & 4 & 8 & 2 & 260 & 525 & $215(40.9)$ & $310(59.0)$ \\
\hline $31-45$ & 130 & 47 & - & 42 & 6 & - & - & 330 & 555 & $220(39.6)$ & $335(60.4)$ \\
\hline $45-60$ & 44 & 58 & 7 & 18 & - & - & - & 140 & 267 & $136(50.9)$ & $131(49.1)$ \\
\hline$>60$ & 12 & 45 & 8 & 39 & - & 4 & - & 91 & 199 & $104(52.3)$ & $95(47.7)$ \\
\hline \multicolumn{8}{|c|}{ Table 5: Shows Age and Sex Wise Distribution of Valvular Heart Diseases } \\
\hline
\end{tabular}

According to WHF criteria of echocardiography for the diagnosis of rheumatic heart diseases, RHD predominantly affects left-sided cardiac valves causing regurgitation, stenosis and mixed haemodynamic effects.

\section{MITRAL VALVE (N=995)}

In our study 995 of 1758 VHD cases of isolated mitral valve diseases were found, of which stenotic lesions of isolated mitral valve diseases (MS and MS with MR) occurs in 706 cases. With the exceptions of congenital (6), degenerative (29), acquired (4) and post-intervention (64) causes, 603 (60.6\%) of 995 cases meets category B (mean gradient $>4 \mathrm{mmHg}$ ) of WHF criteria considered to be isolated rheumatic mitral valve disease in our study.

In our study 6 cases of congenital ( 1 case of subvalvular pathology, 1 case of VSD and 4 cases of ASD), 29 cases 
degenerative, 4 cases were acquired (Vegetations) and 64 cases post intervention were found are excluded to rule out rheumatic heart diseases.

In our study, there is increase in incidence of rheumatic mitral stenosis with age and the most common age group affected were $16-30 \mathrm{yrs}$. and $31-45 \mathrm{yrs}$. and is predominantly found in females as shown in Figure 1.

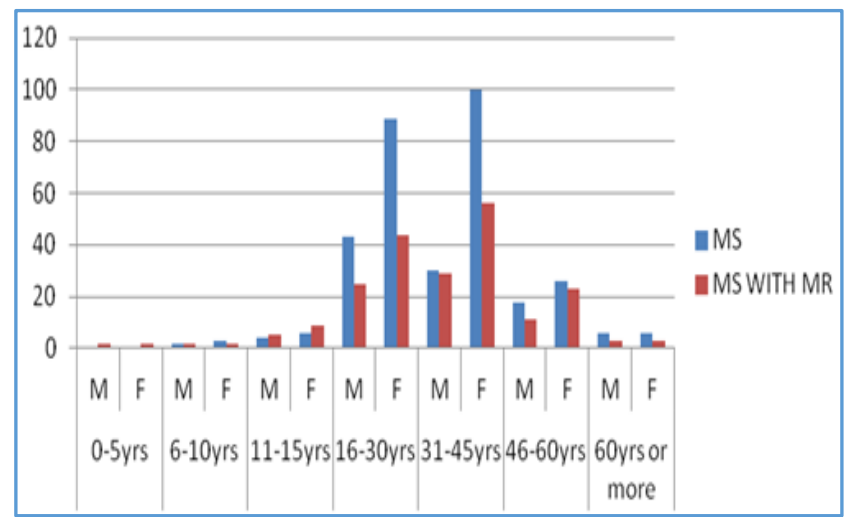

Fig. 1: Shows the Rheumatic Mitral Stenosis in our Study

$980(55.7 \%)$ cases of mitral stenosis (Isolated and combined) is found of 1758 VHD in the present study. Most of them found to have severe MS (61.6\%) with orifice size $<1$ $\mathrm{cm}^{2}$ followed by moderate MS (28\%) followed by mild MS $(10.4 \%)$ as shown in Figure 2. Severe MS is predominantly found in females in our study.

$273(27.8 \%)$ cases of mitral stenosis out of 980 MS were associated with pulmonary hypertension in our study. In our study, there is an increase in incidence of pulmonary hypertension with severity of MS as shown in Figure 2 and is predominantly found in females.

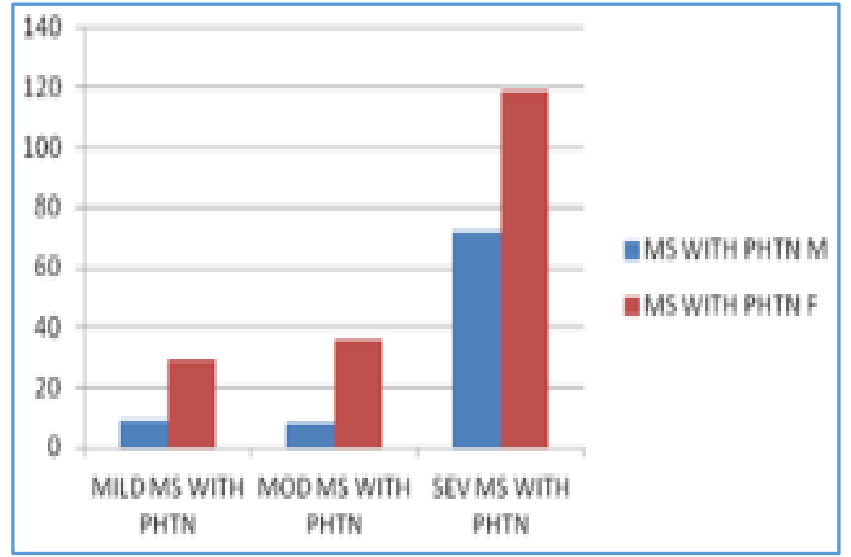

Fig. 2: Shows the Severity of Mitral Stenosis associated with Pulmonary Hypertension

$289(29.0 \%)$ cases out of 995 isolated mitral valve diseases of isolated MR were found in our study, of which 72 cases meets the WHF echocardiography criteria "category A" for the diagnosis of RHD, 38 cases associated with MVP (Myxomatous), 126 cases associated with ischaemic heart diseases, 8 cases associated with hypertensive heart diseases and 45 cases were associated with mitral annular calcification (Degenerative).

Isolated MR predominantly affects females in the present study with peak age of 16-30 yrs. and 45-60 yrs. as shown in Figure 3.

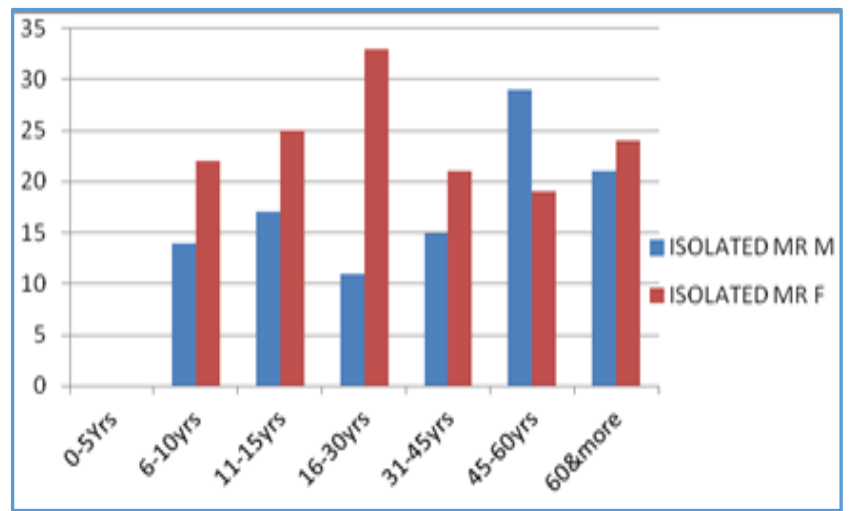

Fig. 3: Shows Isolated MR in the Present Study

\section{AORTIC VALVE (N=728)}

$728(41.4 \%)$ cases of either isolated and combined aortic valve were found in the study, of which 16 cases associated with bicuspid aortic valve (Congenital), 15 cases associated with isolated AS, all of them of degenerative ( $>50 \mathrm{yrs}$.) in our study, 73 cases of AS with AR were found of which 62 of 73 cases were found to be of age $>35$ yrs. considered to be degenerative (CARDIA study) according to WHF echo criteria subcategory $\mathrm{C}$ and 11 cases of 73 does not meet any of the criteria for RHD.

175 (9.95\%) cases of isolated AR were found in the present study and none of them meets the WHF diagnostic criteria of echo for RHD after the exclusion of 15 cases of dilated aortic valve, 7 cases of hypertensive heart diseases, 19 cases associated with ischemic heart diseases, 102 cases were degenerative, 6 cases post intervention, 15 cases were acquired (Vegetations), 11 cases with thickened aortic valve and all of them found in $>50 \mathrm{yrs}$. and not meet the criteria for RHD.

$449(25.5 \%)$ cases of combined aortic and mitral valve were found and are rheumatic according to WHF echo criteria of multivalvular heart diseases for RHD, which says all the aortic valve combined with mitral are of rheumatic in origin as the morphological features that confirms the RHD aetiology takes times to develop.

\section{TRICUSPID VALVE $(\mathbf{N}=\mathbf{2 8})$}

The tricuspid valve and (sometimes) the pulmonary valve can also be affected, but rarely (If ever) without MV involvement (99.3\% on echocardiography and $100 \%$ postmortem examination have coexisting disease of $\mathrm{MV}$, level 1+ evidence of guidelines of SIGN).

In our study, 12 cases of tricuspid stenosis were found and all of them associated with mitral stenosis and therefore rheumatic in origin.

16 cases of isolated tricuspid regurgitation were found considered to be either trivial or unspecified.

\section{PULMONARY VALVE (N=7)}

7 cases of pulmonary valve were found in the study, of which 5 cases were associated with VSD (Congenital), 2 cases were isolated PR either trivial or functional or unspecified.

With the above mentioned analysis, we found the aetiology of different valvular heart diseases in the present study according to WHF echo criteria as shown in Table 6. 


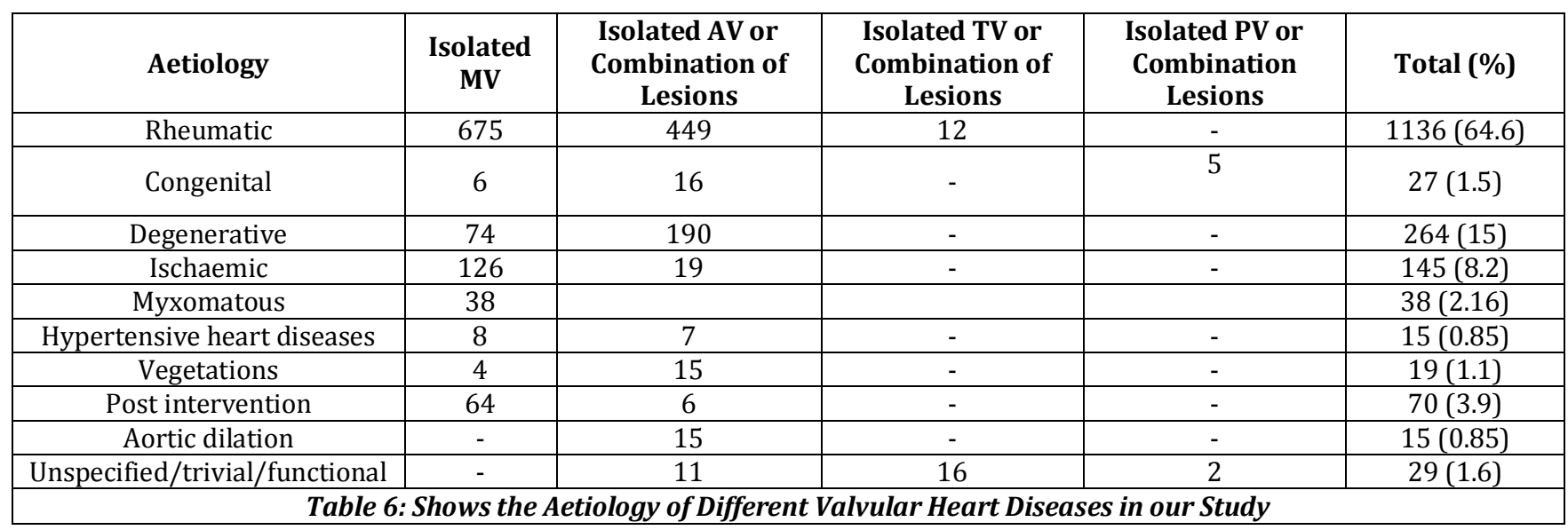

\section{Multivalvular Diseases}

Multivalvular valves were involved in more than half (51.8\%) of total VHD found in the present study. The three most common pattern of multivalvular lesions in the present study were MS with MR (40.8\%) followed by MS with AR (23.1\%) and MR with AR (17.9). Distribution and patterns of involvement of multivalvular heart diseases were shown in Table 4 and Figure 4. Most common was MS with MR and is predominantly found in females.

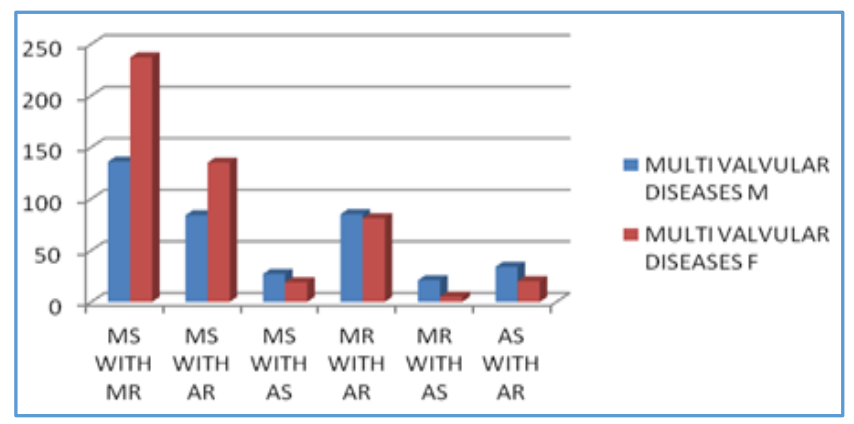

Fig. 4: Shows Combined Valvular Lesions in RHD

\section{SUMMARY}

In the present study of 10,000 consecutive cases undergoing echocardiography, 1758 cases were found to have valvular heart diseases. Out of 1758 cases, VHD 1136 (64.6\%) cases of RHD were found in the present study. Isolated rheumatic mitral valve diseases were 675 (59.4\%) followed by aortic combined with mitral 449 (39.5\%) followed by tricuspid combined with other valve $(1.06 \%)$ and none of the cases of pulmonary valve is rheumatic in origin; $27.8 \%$ cases of MS were associated with pulmonary hypertension in overall VHD in the study and is predominant in females; 15 cases of isolated AS were found in the study and all of them were of degenerative; 12 cases of tricuspid stenosis and all of them associated with mitral and other valves and is rheumatic in origin; 5 cases of pulmonary stenosis were found and all of them associated with VSD and is congenital; 912 cases of multivalvular heart diseases were found of which MS with MR is the commonest in the present study followed by MS with AR followed by MR with AR.

\section{DISCUSSION}

Rheumatic heart diseases are the most common heart diseases in children and young adults. The prevalence of RHD varies among different nations. Highest prevalence in developing countries Bhaya et al. ${ }^{27}$ (51/1000) and least in the developed nation where prevalence is $<1 / 1000$, Bose VJ et al. $0.68 / 1000$, Grover et al. 0.09/1000. In the present study, 64.6\% RHD contributed most of the burden of valvular heart diseases which is similar to the study by Manjunathan C. N. et al.28 (64.3\%) and Radhakrishanan D (68\%). ${ }^{29}$ In India the prevalence of RHD by Padmavati S, Grover et al., Jose VJ et al., Bhaya et al., Saxena. 30 et al. varies from $<1-51 / 1000$. Comparison of RHD in various countries with our studies as shown in Table 7.

\begin{tabular}{|c|c|c|}
\hline Author & Place & $\%$ \\
\hline Our study & Bhopal (MP, Central India) & 64.6 \\
\hline Kutumbiah. ${ }^{31}$ & Madras (Chennai) & 39.5 \\
\hline Bannerjea. $^{32}$ & Calcutta (Kolkata) & 44.6 \\
\hline Sanjeevi. ${ }^{33}$ & Madras (Chennai) & 46.8 \\
\hline Vakil. ${ }^{34}$ & Bombay (Mumbai) & 24.7 \\
\hline Padmawati.35 & Delhi & 39.1 \\
\hline Devichand. ${ }^{36}$ & Shimla & 50.6 \\
\hline Mathur..$^{37}$ & Agra & 35.1 \\
\hline Malhotra. 38 & Punjab & 27.6 \\
\hline Manjunathan C.N. ${ }^{28}$ & Bangalore (South India) & 64.3 \\
\hline Radhakrishnan D. ${ }^{29}$ & Andhra Pradesh & 68 \\
\hline
\end{tabular}

In the present study, isolated mitral valve in the RHD were 59.4 and $39.5 \%$ associated with aortic valve similar to the studies by Manjunath C. N. et al. ${ }^{28}$ (60.2\% and 24.5\%), Radha Krishan D (56\%). ${ }^{29}$

MS with MR (37.5\%) were the commonest VHD in the present study similar to other studies ( $40 \%$ by Dare et al., Waller B et al. and Schoen et al.).6,39,40 Pure MS in our study were $33.5 \%$ similar to the study by Manjunath C. N. et al. (37.1\%).

Isolated MR in the present study were $16.4 \%$, of which $24.9 \%$ rheumatic and 38 cases of 289 were myxomatous. Isolated rheumatic MR is similar to the studies by Olson $(31 \%)^{5}$ and Duren $(40 \%)^{7}$ and myxomatous MR is somewhat lower in the present study as compared to these studies.

$41.4 \%$ aortic valve in the present study, which is higher to other studies by Manjunath C. N. et al. (29.1\%). ${ }^{28}$ and Siddharta et al. (26\%). ${ }^{41}$ Aortic associated with mitral in the study were $25.5 \%$ similar to the studies by C. N. Manjunath (27.2\%) and Siddhartha et al. (26\%).

Multivalvular involvement in our study were 51.8\%, whereas in other studies.28,29 it was lower $18 \%$ by Radhakrishan D. and $36.8 \%$ by Manjunath C. N. et al. In the present study, most common combination involved were MS 
with MR (40.8\%) and second most common were MS with AR (23.1\%) similar to study by Manjunath C. N. (46.6\% and $26.5 \%)$.

In our study, $5.04 \% \mathrm{AS}$ associated with MS similar to the study by Zitnik (6.7\%). 42

In our study, only $1.3 \%$ of tricuspid stenosis were found and all were associated with MS similar to the study by Roberts and Virmani (2\%). 4

In the present study, peak age of valvular heart diseases were $16-30$ yrs. (29.8\%) and 31-45 yrs. (31.6\%) similar to the study by D. Radhakrishnan. ${ }^{16}$ where peak age were $21-30$ yrs. and 31-40 yrs.

Among the overall VHD females (56.75\%) were predominantly involved over males $(43.7 \%)$ similar to the studies by D. Radhakrishnan, Bonow et al., Kutumbiah et al. $29,43,31$

\section{LIMITATIONS}

1. Our study was confined to single tertiary care center, therefore results may differ if some more centers were included within the same district.

2. It is retrospective study, therefore overlapping of lesions may occur. For eg. some cases might have repeat echo (Overlapping).

3. Study conducted had a particular time period, therefore commonest lesions found could be different for different particular period. For eg. In our study MS with MR was the dominant lesions during that period (Selection bias)

4. Aetiology of lesions is strictly based on morphological and clinical criteria. Even early morphological features can be detected by surgical and pathological based studies, as the lesions takes time to develop to be seen by echocardiography.

\section{CONCLUSIONS}

In our study among 10,000 consecutive cases undergoing echocardiography, 1758 cases of valvular heart diseases were found in tertiary care center, Bhopal, MP, Central India. Of these 1758 VHD cases, $64.6 \%$ were found to have rheumatic involvement in the present study. Rheumatic involvement of mitral valve $(59.4 \%)$ is the most common followed by aortic (39.5\%), tricuspid (1.05) and none of the case of pulmonary valve is rheumatic in aetiology. MS with MR is the commonest lesion in our study. Most commonly affected females of 30-45 yrs. age. This study provides unique data of valvular heart diseases suggests that echo is the gold standard for diagnosing and management of VHD, as it clears the anatomy and haemodynamic effects of VHD.

\section{REFERENCES}

1. Carapetis JR. Rheumatic heart disease in developing countries. N Engl J Med 2007;357:439-441.

2. Roberts WC. Morphologic features of the normal and abnormal mitral valve. Am J Cardiol 1983;51(6):10051028.

3. Roberts WC. The congenitally bicuspid aortic valve: a study of 85 autopsy cases. Am J Cardiol 1970;26(1):7283.

4. Roberts WC, Virmani R. Aschoff bodies at necropsy in valvular heart disease. Circulation 1977;57:803-807.
5. Olson LJ, Subramanian R, Ackermann DM. Surgical pathology of the mitral valve: a study of 712 cases spanning 21 years. Mayo Clin Proc 1987;62(1):22-34.

6. Dare AJ, Harrity PJ, Tazelaar HD. Evaluation of surgically excised mitral valves: revised recommendations based on changing operative procedures in the 1990s. Hum Pathol 1993;24(12):1286-1293.

7. Duren DR, Becker AE, Dunning AJ. Longterm followup of idiopathic mitral valve prolapsed in 300 patients: a prospective study. J Am Coll Cardiol 1988;11(1):42-47.

8. Hauck AJ, Freeman DP, Ackermann DM. Surgical pathology of the tricuspid valve: a study of 363 cases spanning 25 years. Mayo Clin Proc 1988;63(9):851-863.

9. Padmavati S. Rheumatic fever and rheumatic heart disease in India at the turn of the century. Indian Heart J 2001;53:35-37.

10. Pilot Study on the Feasibility of Utilizing the Existing School Health Services in Delhi for the Control of RF/RHD. ICMR. final report 1990.

11. Grover A, Dhawan A, Iyengar SD, et al. Epidemiology of rheumatic fever and rheumatic heart disease in a rural community in northern India. Bull World Health Organ 1993;71(1):59-66.

12. Patel DC, Patel NI, Patel JD, et al. Rheumatic fever and rheumatic heart disease in school children of Anand. J Assoc Physicians India 1986;34(12):837-9.

13. Avasthi G, Singh D, Singh C, et al. Prevalence survey of rheumatic fever (RF) and rheumatic heart disease (RHD) in urban \& rural school children in Ludhiana. Indian Heart J 1987;39(1):26-8.

14. Thakur JS, Negi PC, Ahluwalia SK, et al. Epidemilogical survey of rheumatic heart diseases among school children in the Shimla hills of northen India: prevalence and risk factors. J Epidemiol Community Health 1996;50(1):62-67.

15. Lalchandani A, Kumar HR, Alam SM, et al. Prevalence of rheumatic fever and rheumatic heart disease in rural and urban school children of district Kanpur (UP). Indian Heart J 2000;52:672.

16. Jose VJ, Gomathi M. Declining prevalence of rheumatic heart disease in rural school children in India: 20012002. Indian Heart J 2003;55(2):158-60.

17. Periwal KL, Gupta BK, Panwar RB, et al. Prevalence of rheumatic heart disease in school children in bikaner: an echocardiographic study. J Assoc PhysiciansIndia 2006;54:279-82.

18. Rama Kumari N, Bhaskara Raju I, Amar N Patnaik, et al. Prevalence of rheumatic and congenital heart disease in school children of Andhra Pradesh, South India. J Cardiovasc Dis Res 2013;4(1):11-14.

19. Mathur KS, Wahal PK. Epidemilogy of rheumatic heart disease-a study of 29,922 school children. Indian heart journal 1982;34(6):367-71.

20. Padmavathy S. Rheumatic heart disease in developing countries. Bull WHO 1978;56(4):543-55.

21. Roy SB. Prevalence of rheumatic fever and rheumatic heart disease in Ballabhgarh. Annual Report, Indian Council of Medical Research 1968-1969;52.

22. Mathur KS, Banerji SC, Nigam DK, et al. Rheumatic heart disease and rheumatic fever-prevalence in a village community of bichpuri block agra. J Assoc Physicians India 1971;19(2):151-6. 
23. Berry JN. Prevalence survey of chronic rheumatic heartdisease and rheumatic fever in Northern India. $\mathrm{Br}$ Heart J 1972;34:134-49.

24. Agarwal AK, Yunus M, Ahmad J, et al. Rheumatic heart disease in India. J R Soc Health 1995;115(5):303-309.

25. Melvin DC, William FA, Gerard PA, et al. A report of the American college of cardiology/American heart association task force on practice guidelines (ACC/AHA/ASE committee to update the 1997 guidelines for the clinical application of echocardiography). Circulation 2003;108:1146-1162.

26. Reményi B, Wilson N, Steer A, et al. World heart federation criteria for echocardiographic diagnosis of rheumatic heart disease-an evidence-based guideline. Nat Rev Cardiol 2012;9(5):297-309.

27. Bhaya Maneesha, Panwar Sadiak, Beniwal Rajesh. High prevalence of rheumatic heart disease detected by echocardiography in school children. Echocardiography 2010;27(4):448-453.

28. Manjunath $\mathrm{CN}$, Srinivas $\mathrm{P}$, Ravindranath $\mathrm{KS}$, et al. Incidence and patterns of valvular heart disease in a tertiary care high-volume cardiac center: a single center experience. Indian Heart J 2014;66(3):320-326.

29. Radha Krishnan D, Srinivas V. The study of prevalence and clinical profile of valvular heart diseases in a teaching hospital. Jebmh 2015;18(2):2707-2718.

30. Saxena Anita, Ramakrishnan Sivasubramanian, Roy Ambuj. Prevalence and outcome of subclinical rheumatic heart disease in India: the RHEUMATIC (Rheumatic heart echo utilisation and monitoring actuarial trends in Indian children) study. Heart 2011;97(24):2018-2022.

31. Kutumbiah P. Rheumatism in childhood and adolescence part 1. Indian J Pediatr 1941;8:65-86.

32. Banerjea JC. Incidence of rheumatic heart disease in India. Indian Heart J 1965;17:201-2.

33. Sanjeevi KS. Heart disease in south India. Proceedings of association of physician India (Quoted by ref. 35) 1946.
34. Vakil RJ. Heart disease in India. Am Heart J 1954;48(3):439-48.

35. Padmavati S. A five year survey of heart disease in Delhi (1951-1955). Indian Heart J 1958;10:33-40.

36. Devichand. Etiology and incidence of heart disease in India, with special reference to acquired valvular lesions. Indian Heart J 1959;11:117-9.

37. Mathur KS. Problem of heart disease in India. Am J Cardiol 1960;5:60-5.

38. Malhotra RP, Gupta SP. Rheumatic heart disease in Punjab with special emphasis on clinical patterns that differ fromthose reported already. Indian Heart J 1963;15:107-13.

39. Waller B, Howard J, Fess S. Pathology of mitral stenosis and pure nitral regurgitation-part I. Clin Cardiol 1994;17(6):330-6.

40. Schoen EJ, John Sutton M. Contemporary pathologic considerations in valvular heart disease. In Virmani $\mathrm{R}$, Atkinson JB, Feuglio JJ. Cardiovascular pathology. Philadelhia, WB saunders Co, 1991;p334.

41. Siddharth Vinod Lakhani, Vijay Krishna Joglekar. Clinical study of valvular heart disease. Journal of medical thesis 2013;1(1):8-11.

42. Zitnik RS, Piemme TE, Messer RJ. The masking of aortic stenosis by mitral stenosis. Am Heart J 1965;69(1):2230.

43. Bonow RO, Carabello BA, Chatterjee K, et al. ACC/AHA 2006 guidelines for the management of patients with valvular heart disease: areport of the American college of cardiology/ American heart association task force on practice guidelines (writing committee to revise the 1998 guidelines forthe management of patients with valvular heart disease): developed in collaboration with the society of cardiovascular anesthesiologists: endorsed by the society for cardiovascular angiography and interventions and the society of thoracic surgeons. Circulation 2006;48(3):e1-148. 